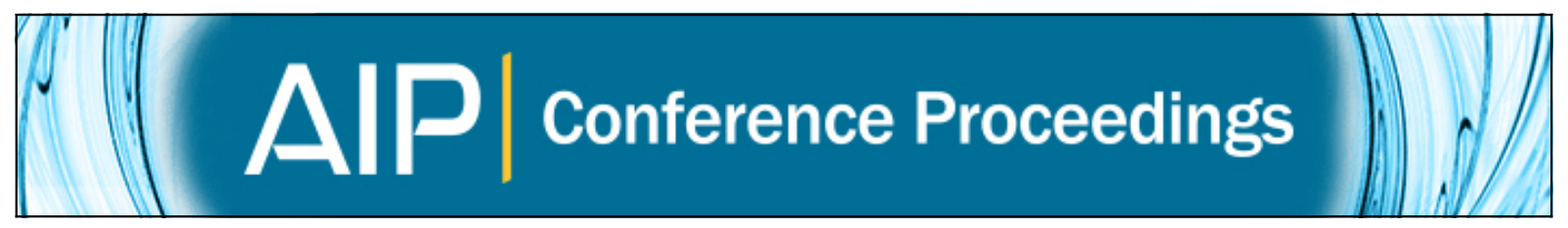

Analyzing materials in the microscopes: From the Sorby thin sections up to the nondestructive large chambers

Javier Garcia-Guinea, Fernando Garrido, Paula Lopez-Arce, Laura Tormo, Alberto Jorge, Marta Furio, and

Cristina Paradela

Citation: AIP Conference Proceedings 1742, 020002 (2016); doi: 10.1063/1.4953121

View online: http://dx.doi.org/10.1063/1.4953121

View Table of Contents: http://scitation.aip.org/content/aip/proceeding/aipcp/1742?ver=pdfcov

Published by the AIP Publishing

Articles you may be interested in

Ultrasonic spectroscopy in non-destructive testing (NDT) of materials

AIP Conf. Proc. 1433, 408 (2012); 10.1063/1.3703215

Towards Large-Scale, Non-Destructive Inspection of Concrete Bridges

AIP Conf. Proc. 760, 1446 (2005); 10.1063/1.1916841

Analysis of Microstructure Using Thermoelectric Diagnostics for Non-Destructive Evaluation of Materials AIP Conf. Proc. 760, 1308 (2005); 10.1063/1.1916823

Non-Destructive Evaluation for Civil Engineering Structures and Materials

AIP Conf. Proc. 700, 32 (2004); 10.1063/1.1711603

Non-Destructive Testing

Phys. Today 15, 62 (1962); 10.1063/1.3058333 


\title{
Analyzing materials in the microscopes: From the Sorby thin sections up to the non-destructive large chambers
}

\author{
Javier Garcia-Guinea ${ }^{1, a)}$, Fernando Garrido ${ }^{1}$, Paula Lopez-Arce ${ }^{1}$, Laura Tormo ${ }^{1}$, \\ Alberto Jorge $^{1}$, Marta Furio ${ }^{1}$, Cristina Paradela ${ }^{1}$. \\ ${ }^{1}$ Museo Nacional Ciencias Naturales (MNCN-CSIC). Calle Jose Gutiérrez Abascal 2 Madrid, 28006 SPAIN

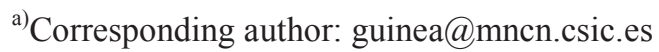

\begin{abstract}
One hundred and sixty five years ago, Henry Clifton Sorby developed a revolutionary technique to prepare thin and polished sections of rocks and minerals to be observed by transmission and reflectance in the optical polarized light microscopes. Nowadays, Sorby's methods are still employed for near all inorganic materials with scarce modifications. The optical microscopy subject is essential for rocks analysis; it is an irreplaceable technique for specific complex samples, such as twinned-exsolved feldspars and it must be preserved in the geosciences curriculum. However, for many valuable and common specimens we observe a strong growing of non-destructive techniques coupled to the large chambers of modern microscopes including new chemical, molecular, luminescent, metrical, imaging and structural probes. Suitable explanations for the thin sections decreasing in research laboratories could be: (i) the undesirable cutting of the specimen; (ii) the contamination of surfaces by abrasives and glues; (iii) the etching with dangerous acids; (iv) the slow and painful works of cutting, grinding and polishing specimens; (v) the necessary protection of valuable specimens, (vi) the need for immediate analytical results.
\end{abstract}

\section{INTRODUCTION}

Since the most ancient time humans have used fire extracting metals by burning mineralized rocks. We have also cut marble to make objects detecting different grain sizes and internal impurities. However, many problems arose studying inside the rocks up to 1849 when Henry Clifton Sorby pioneered a new branch of the Geology the so-called Petrography, i.e., the microscopic examination of very thin sections of rocks. Sorby prepared many thin sections ground to about a thousandth of an inch, close to the $0.03 \mathrm{~mm}$, now the standard thickness for the routinely petrological work (1-3). The Sorby sections were sufficiently thin to admit the use of transmitted light with magnifying powers. Probably the window open once by Sorby thin sections into the materials inside was as important as the present day window open by the Hubble telescope out the space outside, in both cases providing new images good enough to create revolutionary Science.

Nowadays, circa 165 years later, the Sorby technique is worldwide accepted and employed for almost all materials in the two different mountings: thin and polished sections to observe materials by transmission and reflectance light. Thin sections and the polarized light optical microscope (PLM) are essential tools to study rocks and perform an irreplaceable technique for specific cases as the observation at low magnification of crystalline and textural details that can be lost with other techniques such as the twinning and exsolution features of feldspars, but probably, it is now the right time to revise all other modern microscopes including the new chemical, molecular, luminescent, metrical, imaging and structural probes. We are not the first authors detecting that the use of the PLM and the teaching of the optical mineralogy is in general decreasing (4). Certainly, M.E. Gunter (4) points that excluding the subject of optical microscopy would be the biggest mistake we have ever made in the geosciences curriculum. He justifies this statement because the fundamentally important concepts presented in optical 
mineralogy: 1) three-dimensional visualization, 2) inquiry-based learning, and 3) hands-on use of an analytical instrument. No other single course in our curriculum provides so many of these fundamental skills to our students. These conclusions certainly are correct, but we will focus only on the PLM for the analytical sciences studying materials.

The PLM was originally called a mineral microscope because of its applications in petrographic and mineralogical research but nowadays it is only other useful microscope for material analyses. Equally, the "NonDestructive Analysis" concept is rarely considered in the scientific papers up to approximately the nineties of last century while in the last 20 years it had actively grown (5-7). The 20th century was a transitional period from the chemical determinations using blow-pipes to analyze presence of metals in rocks, to the chemical analyses in the arc spectrographs, the chemical wet routines, and inductively coupled plasma and finally, the appearance of the electron probe microscopes in the seventies which perform micro-spot analysis on specific grains of the traditional thin and polished sections. Finally, the energy X-ray dispersive spectroscopy probes (EDS) allow the exploration of almost all the elements of the periodic system and they could be coupled to very other different apparatus (TEM, Raman, ESEM, etc.) (8-9). Concerning minerals identification, during the first half of the 20th century, it was frequent to use Mineral Tables for the determination of minerals by their physical properties. The Mineral Table includes common minerals arranged by arranged primarily by streak and color, including also luster, hardness, specific gravity, crystallization, twinning, cleavage, fracture, tenacity and structure (10). Nowadays, modern instrumental techniques are used to identify mineral samples, although simple chemical testing, in conjunction with determination of hardness and specific gravity, provide valuable information about the nature of a mineral. Currently, it is widely recognized that in addition to the mineralogy and petrography basic chemistry courses are also desirable components of the Geoscience Curriculum (11).

The traditional Gemology curriculum includes non-destructive methods identifying gemstones supported in physical measurements, such as specific gravity (hydrostatic balance), refraction index (refractometer), spectral lines (optical spectrometer), optical anisotropy (polariscope), or internal inclusions (gemolite microscope), etc. However, this complete set of gemological micro-devices just only provides simple numbers as refraction index or specific gravity which frequently do not allow unequivocal determination using gemological tables. Conversely, a modern Raman pattern can be searched automatically using powerful open-access mineral Raman databases, such as the case of RRUFF database of the Arizona University. The polarized light microscope (PLM), the Mineral Tables for the determination of minerals by their physical properties, the traditional Gemology devices and the basic crystallography and chemistry skills are convenient in most of the programs on Gemology, Forensic, Earth and Materials Sciences. However, the modern microscopes including the new analytical probes allow for cost- and timeeffective analysis of materials preserving samples using the so-called sets of Non-Destructives Techniques.

Our Institute, the National Museum of Natural Sciences (CSIC, Madrid) keeps together a traditional laboratory of petrography and polarized light microscopes with new equipment of non-destructive techniques. For example, a new Leica DCM8 microscope has recently been installed as it bonds advantages of high-definition confocal microscopy and interferometry in one instrument. It is a non-contact 3D optical surface profiling. The instrument provides high definition confocal microscopy for high lateral resolution and interferometry to reach sub-nanometer vertical resolution. This new microscope runs as an optical one with bright-field, dark-field and confocal, as well as three interferometric modes. It allows the study of surface roughness of solids following exposure to acidic attacks (12). Certainly, for many years the best preparations of iron and steel under the polarizing microscope were prepared by the combined method published by Sorby (3) involving polishing and etching. He etched his specimens with very dilute solutions of nitric acid and this reagent was widely used for many years. Generally speaking, the new generations of 3D Dual Confocal-Interferometry microscopes, such as Leica DCM8, are good devices for accurate surface roughness measurements and color documentation of samples (13). Meanwhile, in recent years enormous advances and discoveries in the optoelectronics fields have revolutionized the analytical instrumentation. Good examples are the slow-scan charge-coupled device (CCD) cameras, CMOS detector arrays as photodetectors and autofocusing systems suitable to improve the modern microscopes. The recent Nobel Prizes (2014) "for the development of super-resolved fluorescence microscopy" (Chemistry: Eric Betzig, Stefan W. Hell and William E. Moerner) and "for the invention of efficient blue light-emitting diodes which has enabled bright and energy-saving white light sources (Physics: Isamu Akasaki, Hiroshi Amano and Shuji Nakamura) are excellent examples of these extraordinary developments. In addition, reference databases of Raman and luminescence spectra are continuously improving the operation of the analytical facilities (Figure 1). The effectiveness analysis of samples in ESEM 
chambers is based on correct identifications of inorganic phases held within large complex textures through the assessment of their physical-chemical properties avoiding dehydration and no need of sputter coating of the sample. Nowadays it seems interesting to perform measurements onto larger polished surfaces looking for all possible chemical elements and collecting chemical, molecular, structural and luminescent spectra with spatial resolution using the manageable analytical probes, e.g., CL, EDS, BSED, Raman, etc. The analytical productivity increase can be expressed in terms of phases determined, squared centimeters analyzed, number of samples, solid-state processes inferred, etc. Our daily experience working in the ESEM system at the MNCN (Museo Nacional de Ciencias Naturales, Madrid, Spain) demonstrates that for many common substances (pigments, fossils, gemstones, minerals, rocks, terracotta, alloys, etc.) after the ESEM analyses, only occasionally it is required to use our Raman-PL optical microscope and/or to record extra X-ray diffractograms. In the MNCN facilities we are observing a progressive reduction of the applications for polished sections of sliced rocks and inlaid metal ores to be used in the optical microscopes by transparency (rocks) and reflection (metallic ores). The introduction of new in-house facilities in our research center such as CT-Scan, CLSM and 3DCIM let us to consider new strategies to optimize geomaterial analyses using accessible facilities preserving specimens, time and consumables.

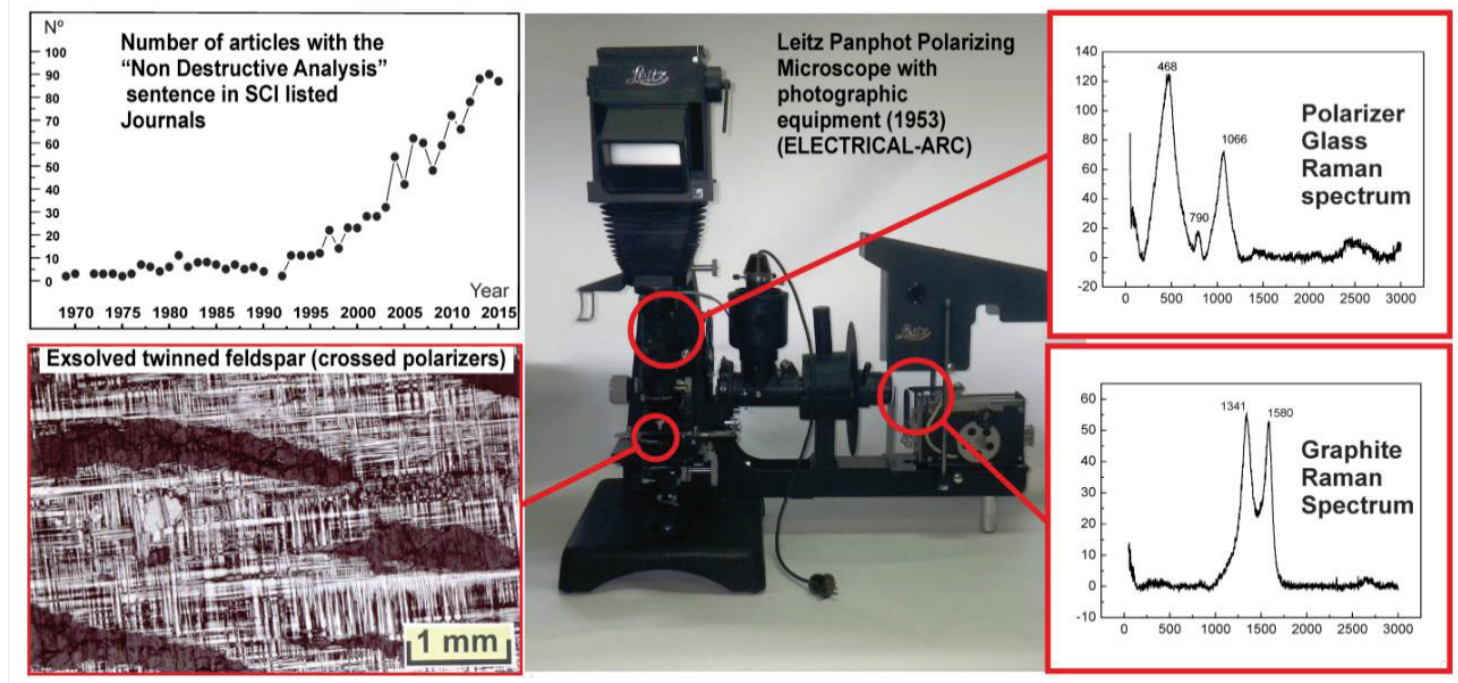

FIGURE 1. The Sorby thin sections of complex twinned feldspars can be observed in a Leitz Panphot (1953) as delicate coloured images, and the Raman microscopes with large chambers can analyze both, organic and inorganic components.

\section{SAMPLES AND TECHNIQUES}

We have examined morphological and structural properties of historical thin sections using a polarized optical microscope Nikon, ECLIPSE E600 POL which features a 12 volt-100 watt internal tungsten halogen illumination system that tunnels through the base to provide bright and stable diascopic Köhler illumination. We have also studied some components, such as graphite, polarizing glass and collodion plates by means of our Leitz Panphot petrographic microscope (1953) since it was the first truly universal stand for photomicrography. Currently, the Raman analyses are usually performed in non-destructive way using a Thermo-Fischer DXR Raman Microscope (West Palm Beach, FL 33407, USA) which has a point-and shoot Raman capability of one micron spatial resolution using a laser source at $532 \mathrm{~nm}$. Additional samples of natural samples of poly-mineral quartz mineralization are commonly selected to test our modern microscopes. Microscopy observations, chemical analyses and CL measurements, such as spectral curves, panchromatic and monochromatic plots are performed by environmental scanning electron microscopy coupled with energy dispersive X-ray spectroscopy (ESEM-EDS) or coupled with wavelength dispersive X-ray spectroscopy (ESEM-WDS) using an Inspect and Quanta 200 ESEMs of the FEI Company. Similarly, the images of the natural quartz sample are collected in a new 3D White Light Interferometry microscope of Leica DCM8 using four LED light sources - blue $(460 \mathrm{~nm})$, green $(530 \mathrm{~nm})$, red $(630 \mathrm{~nm})$, and white (centered $550 \mathrm{~nm}$ ) - and an integrated CCD camera deliver true-to-life color images. The camera has a large field of 
view, and $\mathrm{XY}$ topography-stitching mode to get all-in-one, specific model of a bigger area. The software allows for the simplification of complicated $3 \mathrm{D}$ and 2D color image analyses.

\section{RESULTS AND DISCUSSION}

The geological observations of Sorby under thin sections and their further significance

Henry Clifton Sorby published a pioneer paper entitled "On the microscopical structure of crystals, indicating the origin of minerals and rocks" (1). One hundred and sixty five years later, it is very interesting to re-visit the relevance of their findings and how they have been improved using modern techniques (Figure 2). The polarizing microscope is still being employed for investigating optical properties of very different materials; this equipment is being used in very diverse fields as biology, medicine, polymer chemistry, liquid crystals, magnetic memory, and state-of-the-art materials. Many of the modern analyses of the Sorby's questions and answers have only been studied in depth in the last fifty years. For example, Sorby discovered cavities and porosity in rocks which nowadays generate crucial problems in both, architectural heritage and modern construction, since soluble salts greatly limit the durability of porous building materials (14-15). Specific techniques are developed to measure closed and open porosity via intrusion of gas, either gas (helium) or liquid (mercury) into the rock at different pressures, or through computational analysis from 2D images taken from the microscopes or by 3D CT Scan analyses (16).

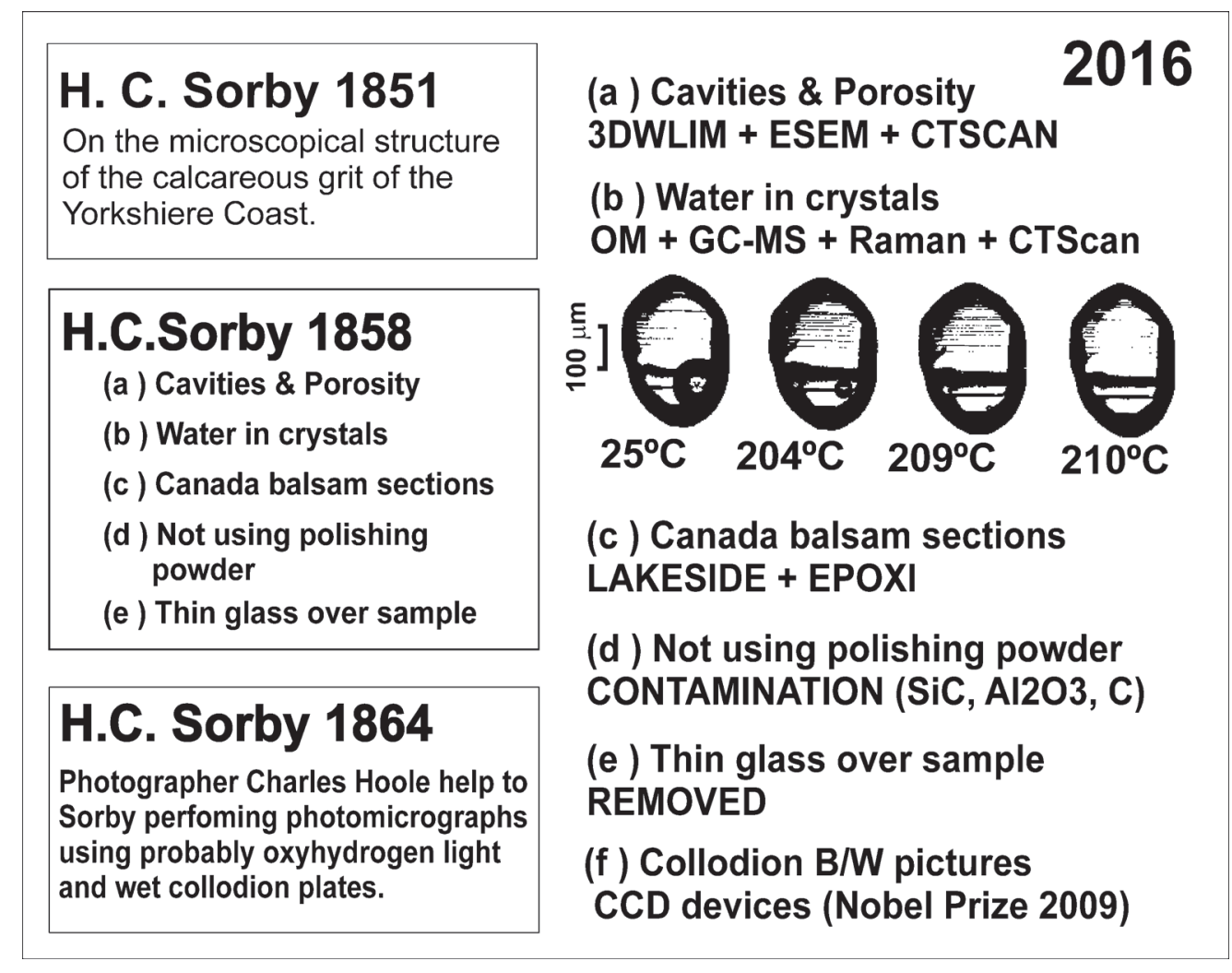

FIGURE 2. Milestones of Henry Clifton Sorby observing rocks, minerals and metals under the optical microscope, together with modern techniques to study their suggested geological questions.

The first X-ray micro-tomography system was conceived and built by Jim Elliott in the early 1980s publishing $\mathrm{X}$-ray micro-tomographic images reconstructing slices of a small tropical snail, with pixel size about 50 micrometers (17). The X-ray computed tomography, often referred to as CT scan, X-ray CT, or simply CT, works by recording the quantity of X-ray energy transmitted across the sample as it is rotated, as a result, X-ray images are collected during a single $360^{\circ}$ scan. From this set of projection images rebuilding algorithms can generate cross-sectional 
slices through the specimen perpendicular to the axis-of-rotation. These cross-sectional slices can be stacked to form a 3D model of the sample. Later, software imagining tools can be used to manipulate the 3D model from any viewpoint. Both examination and measurement tasks can be implemented depending on the specific application.

Micro-CT-Scanners allow obtaining internal images from the objects with dissimilar inner densities, like stoneair (porosity). Both, outcropped cavities and porosity in a sliced rock can also be studied by surface metric techniques. This is the case of our new 3D-Confocal-Profilometer-Microscope (3DCPM) which combines interferometry and confocal topography concepts on one stand, offering phase shifting and white light interferometry to characterize very smooth surfaces (Figure 3). This new optical microscope provides novel interferometric and confocal colored images taken directly from slice surfaces, useful for crystallographic and metric measurements. This tedious way of sample preparations such as those by the polarizing microscopes could perhaps be circumvented.

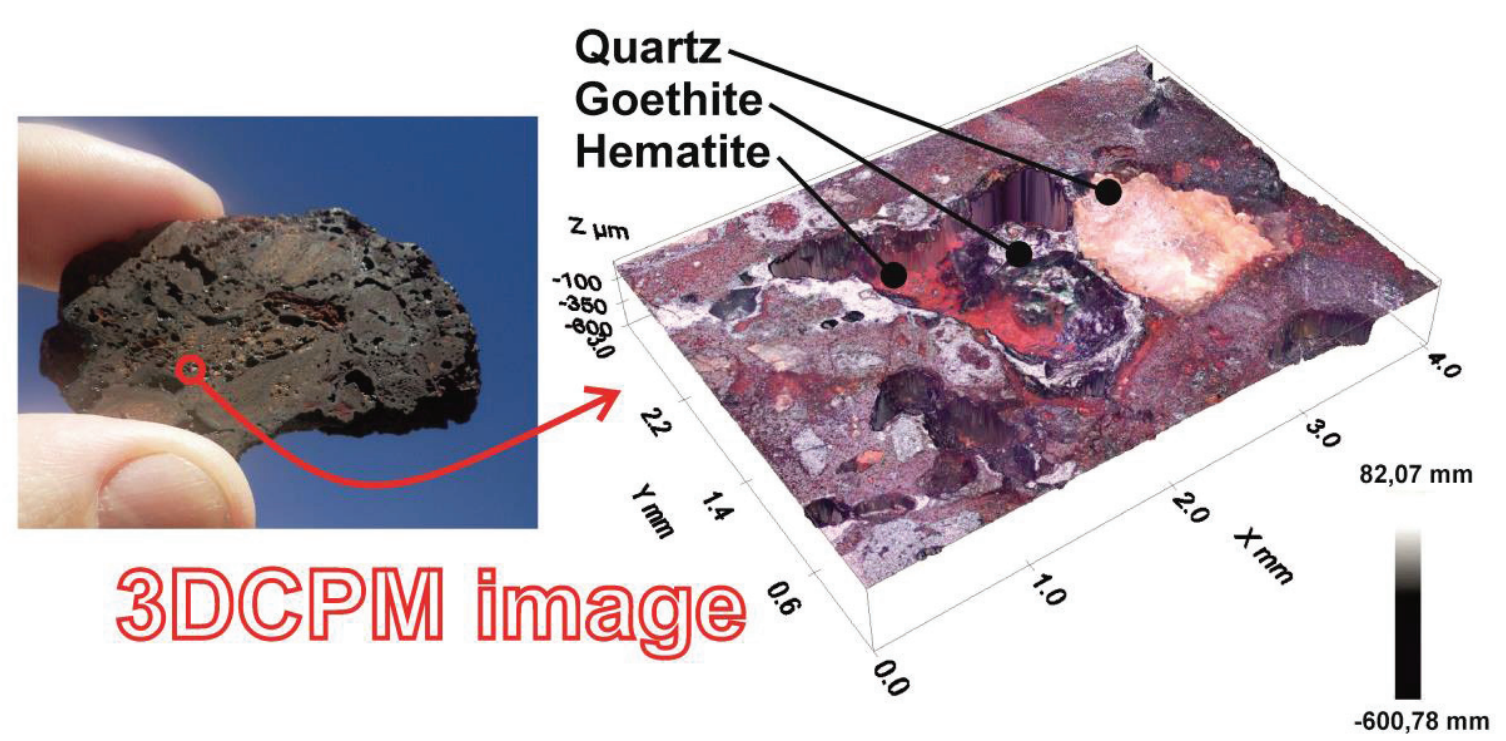

FIGURE 3. Quartz-Iron Oxides from the Riotinto iron slags (Huelva, Spain). Recent 3D measurement performed by the focus variation method in a Leica DCM8 3D-Confocal-Profilometer Microscope (3DCPM)

Sorby also observed aqueous fluid inclusions in transparent crystals which is other important scientific branch of Geosciences nowadays. These observations were developed to know the temperature formation of hydrothermal veins in ore deposits. The decrepitation method of fluid inclusions in minerals was suggested by Scott in 1948 (17) as a simple technique where in minerals with fluid inclusions are heated until the fluid escapes. By means of this method Scott could infer formation temperatures of primary and secondary inclusions, inversion points, and even data to be used determining depths of minerals formation into hydrothermal systems involved with profitable ore deposits. (17). Later, in 1984 Roedder published a large monography review on all types of fluid inclusions (gas, liquid, or melts) trapped in materials from earth and space, and their application to the understanding of geological processes (18). As a result, many mineral-related departments bought Linkam stages and temperature controllers to change the sample temperature, e.g., from $\mathrm{N}_{2}-190^{\circ} \mathrm{C}$ to near $300^{\circ} \mathrm{C}$ observing decrepitation and evolutions of fluid inclusions under light polarizer microscopes.

The best recipe to prepare such thin sections to observe fluid inclusions was grinding up to half millimeter in section and polishing both slice sides to improve the fluid inclusions observation. We recommend a precise procedure consisting in gluing one of the polished sections to a glass surface using cyanoacrylate and later dissolving the joint with an organic dissolvent as ketone compounds. In addition, some Earth Science laboratories implemented gas chromatography mass spectrometers (GC-MS) to analyze gases leaked during the decrepitation 
thermal process. In recent time, the confocal micro-Raman microscopes allow to record Raman spectra in automated way, along the $\mathrm{c}$ axis, from the crystal outer surface to the inner fluid inclusion. The new little and accurate microCT-Scan devices can also detect such bubbles holding fluid inclusions. Both, CT-Scan and Raman are nondestructive techniques being unnecessary the sample cutting.

\section{The Sorby method to prepare thin sections and its further evolution}

The method for the preparation of thin sections was developed by Sorby in 1851 but he published it in detail thirteen years later (19). Previously Vogelsang (20) published in 1867 a clear presentation of the fundamental methods to prepare thin sections. Since this date, petrographic techniques were progressively being used in most of the European centers, e.g., in 1870 Jose Macpherson published in Madrid an adaptation-translation of the Sorby method creating a private geological survey which included the preparation of thin sections. The petrographic laboratory and was transferred to the institution "Libre de Enseñanza" after his death in 1902. The original Sorby method for the preparation of rocks that was used the first part of the 20th century involved the use of Canada balsam and the sample destruction by grinding it against an abrasive wheel

Later, in the second half of the 20th century they change the glue to Lakeside Brand Cement, which is colorless in thin films and has refraction index equal to 1.54, very similar to Canada balsam. This glue is fully thermoplastic melting quickly above $80^{\circ} \mathrm{C}$ and flowing freely at $140^{\circ}$ to form a uniform thin film. In the last thirty years the use of epoxy resins along with hardeners co-reactants, such as poly-functional amines, acids, phenols, alcohols and thiols have become the best option. The reaction of poly-epoxides with poly-functional hardeners yields thermosetting polymers with better high mechanical properties, temperature and chemical resistance, similar to those of the thermoplastic compounds, and, accordingly epoxy resin facilitates the stone slicing and the preservation of the sample (Figure 4).

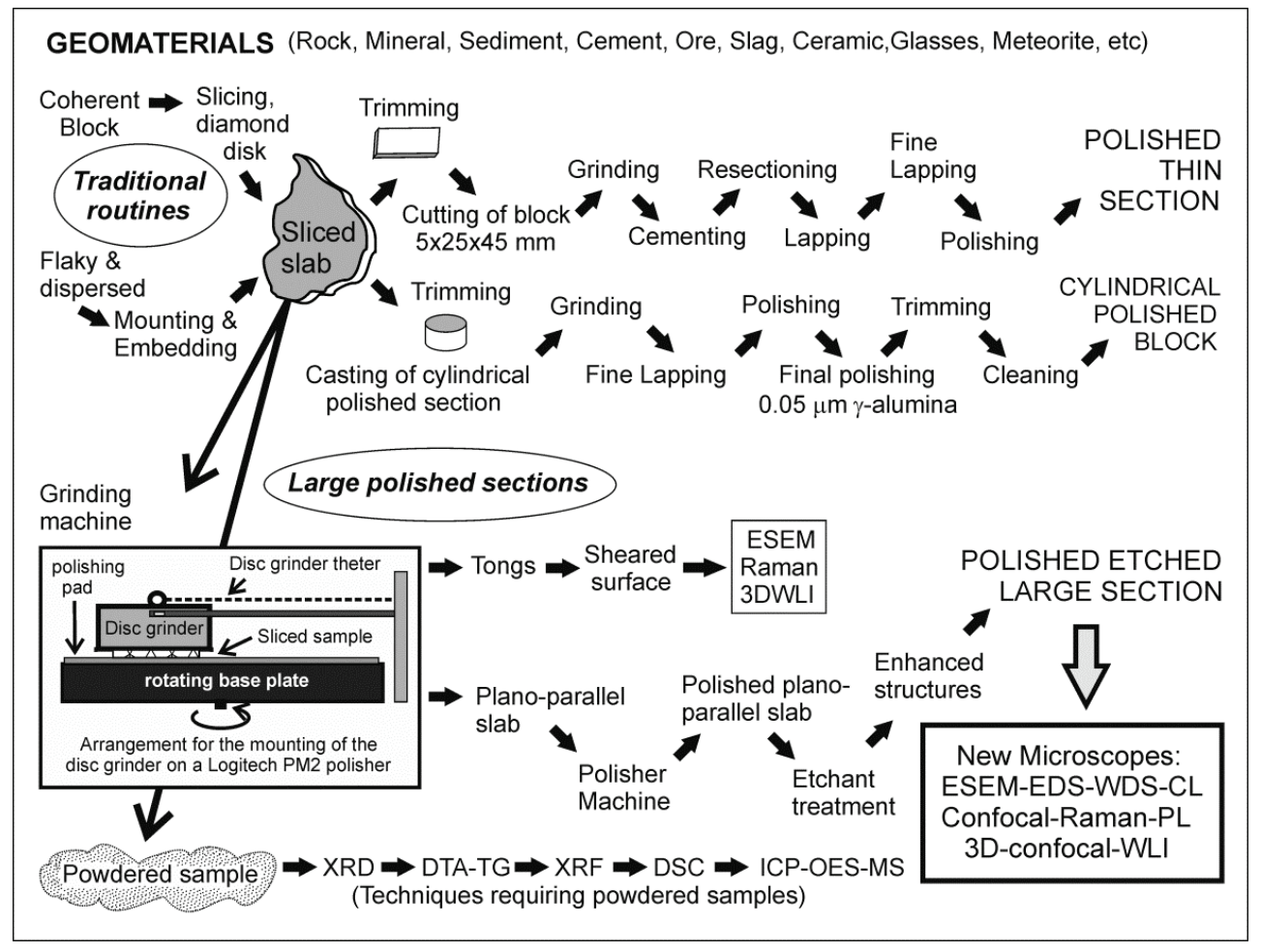

FIGURE 4. Traditional routines (Sorby, 1851) preparing thin and polished sections of inorganic materials and modern new analytical alternatives. 
The history of the development of the techniques for the preparation of thin sections was described by several authors in the first half of the 20th century. A thorough description of the main methods can be found in Rogers and Kerr (1942) book (21). Surprisingly, both the present-day and the Sorby methods to prepare thin and polished sections are very similar including limitations and/or disadvantages such as slow and painful works of cutting, grinding and polishing, as follows: (1) destruction of textures by sample cutting up to circa $3 \times 2 \mathrm{~cm}$ and $1 \times 1 \mathrm{~cm},(2)$ physical destruction of sample by grinding, (3) contamination of surfaces by metallization and different abrasives, (4) etching with dangerous acids. As opposed to them, the new Non-Destructive facilities introduce a large analytical chamber, which eases the study of large specimens with no need of sample manipulation. These new devices include probes for imaging, chemical-elemental, molecular, luminescent, surficial metrics, internal 3D distribution of densities, and structural analyses which circumvent the use of thin and polished sections (Figure 5). Probably the use large chambers to analyze "as received" samples in a non-destructive way let us to reduce such difficulties.

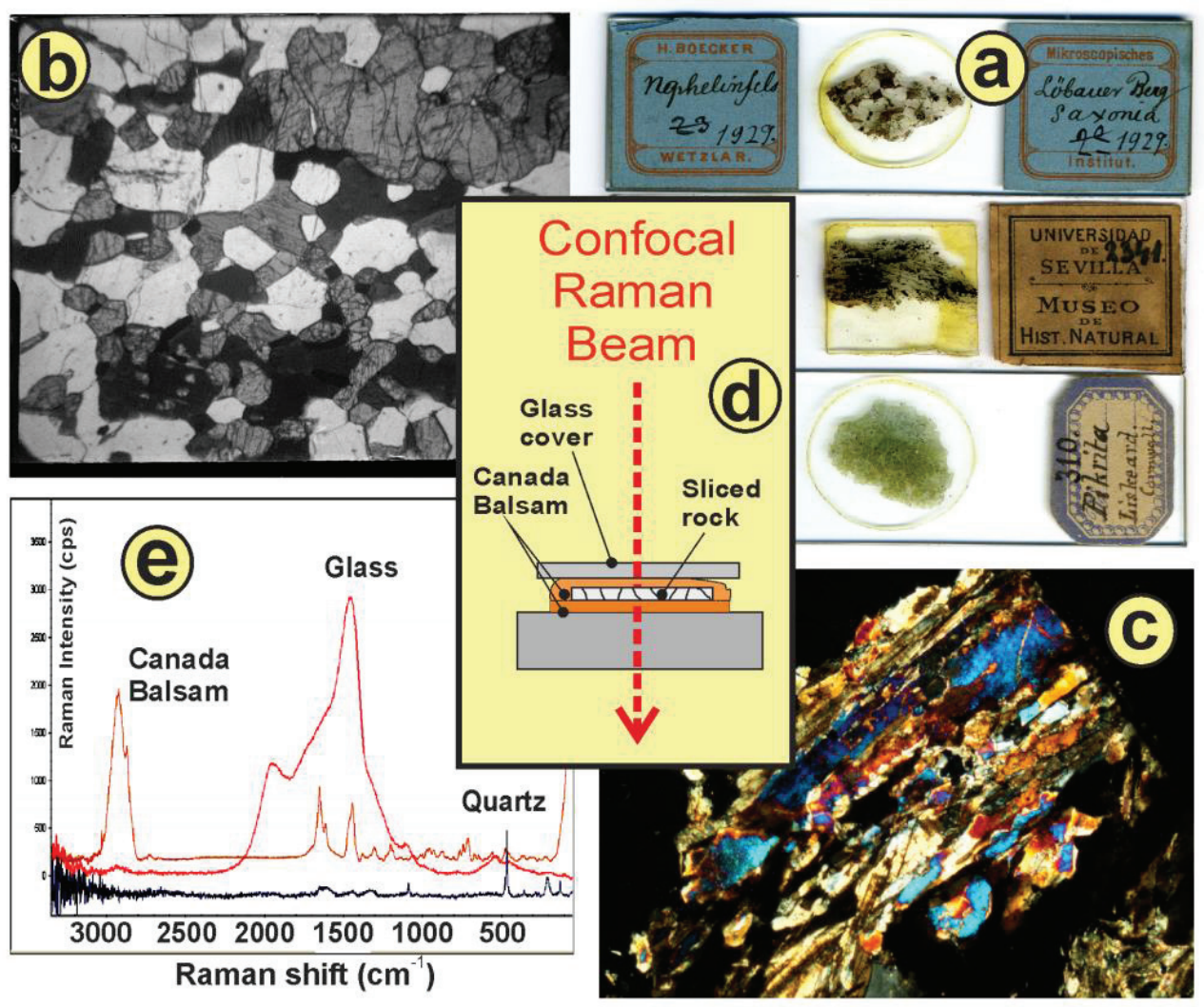

FIGURE 5.- Thin sections of rocks prepared by the Sorby method in Spain and Germany in 1929: (a) Samples of the MNCN Geology Collection (Madrid), (b) Scanned image of a glass-collodion plate photomicrography taken by Jose Maria Fuster Casas from a thin section of rocks from Guinea Equatorial using a Leitz Panphot Polarizing Microscope (1953) with photographic equipment (graphite electrical arc), (c) Crossed polarizers image taken in with modern Nikon eclipse E600Pol petrographic microscope of the same top thin section, (d) Drawing of Confocal Raman analysis schematic with different parts of the same thin section. (e) Resulting Raman spectra of a quartz grain, Canada balsam glue and glass cover of the sample thin section preparation.

\section{CONCLUSIONS}

Nowadays, Sorby methods are employed to prepare thin sections from near all inorganic materials with few modifications. The optical microscopy subject must be preserved in the geosciences curriculum given that is an essential for the analysis of complex rocks. Nevertheless, there is an increasing use of non-destructive techniques associated to the large chambers of modern microscopes including new chemical, molecular, luminescent, metrical, 
imaging and structural probes. These powerful analytical techniques have progressively substituted those ones based on thin sections in modern research facilities, suitable explanations for this tendency could be: (i) the undesirable cutting of the specimen, (ii) the contamination of surfaces by abrasives and glues, (iii) the etching with dangerous acids and (iv) the slow and painful work of cutting, grinding and polishing specimens, (v) the necessary protection of valuable specimens, (vi) to accelerate the results with fast physical-chemical analyses.

\section{REFERENCES}

1. H. C. Sorby 1851. On the microscopical structure of the calcareous grit of the Yorkshire Coast. Quarterly Journal of the Geological Society of London 7, 1-6 (1851).

2. Sorby, H.C. 1858. On the microscopical structure of crystals, indicating the origin of minerals and rocks. Quarterly Journal of the Geological Society of London 14, 453-500 (1858)

3. Sorby, H.C. 1864. On microscopical photographs of various kinds of iron and steel. British Association Reports, Pt. 2, p.189 (1864).

4. M. E. Gunter. The polarized light microscope: should we teach the use of a $19^{\text {th }}$ century instrument in the $21^{\text {st }}$ century. Journal of Geoscience Education 52, 34-44 (2004)

5. K. Janssens, G. Vittiglio, I. Deraedt, A. Aerts, B. Vekemans, L.Vincze, F. Wei, I. Deryck, O. Schalm, F. Adams, A. Rindby, A. Knöchel, A. Simionovici, A. Snigirev. Use of Microscopic XRF for Non-destructive Analysis in Art and Archaeometry, X-Ray Spectrometry. 29, 73-91 (2000).

6. A. K. Cheburkin An energy-dispersive miniprobe multielement analyzer (EMMA) for direct analysis of $\mathrm{Pb}$ and other trace elements in peats Fresenius' Journal of Analytical Chemistry 354, 688-691 (1996)

7. D. C. Smith, M. Bouchard, M. Lorblanchet. An initial Raman microscopic investigation of prehistoric rock art in caves of the Quercy District, S. W. France. Journal of Raman Spectroscopy, 30,347-354 (1999).

8. V. I. Vershinin, Yu. A. Zolotov, Periodization of the history of chemical analysis and analytical chemistry as a branch of science. Journal of Analytical Chemistry 4, 859-867 (2009).

9. A.M. Pollard. Letters from China: A history of the origins of the chemical analysis of ceramics Ambix $\mathbf{6 2}$, 50-71 (2015)

10. A.S. Eakle (1938) Mineral tables for the determination of minerals by their physical properties. Ed. Wiley \& Sons. 3ed. New York.

11. S. Baskerville, W. Evans. Mineral Identification by Chemical Testing. Journal of Geoscience Education 56, 302-306 (2008)

12. C. Poggio, A. Dagna, M. Chiesa, M. Colombo, A. Scribante. Tribology Letters Surface roughness of flow able resin composites eroded by acidic and alcoholic drinks. Journal of Conservative Dentistry 15, 137-40 (2012).

13. N. Schalk, C. Mitterer, C. Czettl, B. Sartory, M. Penoy, C. Michotte. Dry-Blasting of $\alpha$ - and $\kappa-A 12 O 3$ CVD Hard Coatings: Friction Behaviour and Thermal Stress Relaxation. Tribology Letters 52, 147-154 (2013)

14. D. Benavente, M.A. Garcia del Cura, c, J. Garcia-Guinea, S. Sánchez-Moral, S. Ordóñez. Role of pore structure in salt crystallization in unsaturated porous stone. Journal of Crystal Growth 260, 532-544P. M. Doyen, Permeability, conductivity, and pore geometry of sandstone. Journal of Geophysical Research, 93, 7729-7740 (1988).

15. E. D. Pittman, Relationship of porosity and permeability to various parameters derived from mercury injection-capillary pressure curves for sandstone. American Association of Petroleum Geologists Bulletin, 76, 191-198 (1992).

16. Elliott, J. C.; Dover, S. D. "X-ray microtomography". Journal of Microscopy 126, 211-213 (1982).

17. H. S. Scott. The decrepitation method applied to minerals with fluid inclusions. Economic Geology 43, 637-654 (1948).

18. E. Roedder, Fluid Inclusions. Review of the Mineralogical Society of America 12, 650p (1984).

19. H. C. Sorby. Preparation of transparent sections of rocks and minerals: The Northern Microscopist, 17, 101-106, 133-140 (1882).

20. H. Vogelsang Philosophie der Geologie und Mikroskopische Gesteinsstudien. Ed. Max Cohen \& Sohn, Bonn, 229 p. (1867)

21. A. F., Rogers, and P. F. Kerr, Optical mineralogy,2d ed., Book McGraw Hill Co. New York (1942). 